\title{
Article \\ Body Composition Symmetry in Long-Term Active Middle-Aged and Older Individuals
}

\author{
Silvia Stagi ${ }^{1, *}$, Alessia Moroni ${ }^{2}$, Margherita Micheletti Cremasco ${ }^{2}$ (D) and Elisabetta Marini $^{1, *(D)}$ \\ 1 Department of Life and Environmental Sciences, Neuroscience and Anthropology Section, \\ University of Cagliari, Cittadella di Monserrato, 09042 Cagliari, Italy \\ 2 Department of Life Sciences and Systems Biology, University of Torino, 10123 Torino, Italy; \\ alessia.moroni@unito.it (A.M.); margherita.micheletti@unito.it (M.M.C.) \\ * Correspondence: silviastagi@unica.it (S.S.); emarini@unica.it (E.M.)
}

Citation: Stagi, S.; Moroni, A.; Micheletti Cremasco, M.; Marini, E. Body Composition Symmetry in Long-Term Active Middle-Aged and Older Individuals. Int. J. Environ. Res. Public Health 2021, 18, 5956. https://doi.org/10.3390/ ijerph18115956

Academic Editor: Paul B. Tchounwou

Received: 23 April 2021

Accepted: 31 May 2021

Published: 2 June 2021

Publisher's Note: MDPI stays neutral with regard to jurisdictional claims in published maps and institutional affiliations.

Copyright: (c) 2021 by the authors. Licensee MDPI, Basel, Switzerland. This article is an open access article distributed under the terms and conditions of the Creative Commons Attribution (CC BY) license (https:// creativecommons.org/licenses/by/ $4.0 /)$.

\begin{abstract}
This study aimed to analyze body composition and strength symmetry in a sample of 165 middle-aged and elderly Italian volunteers, which included 97 active (67 men and 30 women; $61.17 \pm 7.56$ years) individuals regularly engaged in Tai Chi Chuan, tennis, or running, and a control group of 59 age-matched sedentary (27 men and 32 women) individuals. Anthropometric and bioelectrical measurements and hand grip strength of both sides were collected. Segmental body composition was analyzed through specific bioelectrical impedance vector analysis. The body composition of the right and left limbs was similar among active individuals (arms: $\mathrm{T}^{2}=6.3$, n.s.; legs: $\mathrm{T}^{2}=5.0$, n.s.), with a similar pattern in the three different disciplines. By contrast, the control group showed bilateral asymmetry (arms: $\mathrm{T}^{2}=6.8, p<0.001$; legs: $\mathrm{T}^{2}=8.8, p<0.001$ ), mainly because of the higher values of specific reactance $(\mathrm{t}=2.4 ; p=0.018)$ and phase angle $(\mathrm{t}=2.0 ; p=0.054)$ in the dominant arm, and the higher specific vector length $(t=-3.0 ; p=0.027)$ in the left leg. All of the groups showed a higher hand grip strength in the dominant arm (active: $t=7.0, p<0.001$; control: $\mathrm{t}=2.9 ; p<0.01$ ). In conclusion, the active individuals showed stronger body composition symmetry than the controls, thus indicating a previously undetected positive effect of sport in middle-aged and older adults.
\end{abstract}

Keywords: body symmetry; segmental body composition; bioelectrical impedance vector analysis; BIVA

\section{Introduction}

The ageing process exposes the older population to the risk of malnutrition, sarcopenia, sarcopenic obesity, and frailty. These conditions can significantly accelerate functional decline and increase the risk of morbidity and falls, which in turn are related to a greater risk of mortality [1]. Such a scenario is exacerbated when combined with psychological disorders, physical inactivity, or poor dietary habits.

Physical activity (PA) can effectively contribute to the maintenance of well-being in the elderly, thus representing a driving force for successful ageing. Indeed, PA helps counter the age-related trend toward a decline of muscle mass and functionality, and an increase and central accumulation of fat mass (FM) [2,3]. Accordingly, the World Health Organization recommends PA and muscle strengthening training for maintaining physical, psychological, and cognitive well-being in older-aged individuals [4]. Older people should also exercise to improve their balance and prevent falls in daily living.

Body asymmetry, specifically, strength, functionality, and body composition asymmetry, could interfere with physical balance and risk of falls. Sports science highlights the relevance of maintaining body symmetry in order to improve technical proficiency performance and to prevent injuries [5]. In the older population, the literature shows a positive correlation between asymmetry and functional disabilities, body balance, and falls [6-10]. However, research in the older population mainly refers to strength and 
functional asymmetry, while the role of body composition asymmetry has been poorly investigated. Moreover, to the best of our knowledge, only a few studies have investigated the effects of PA on body composition asymmetry in older individuals, and participants were limited to tennis players [11,12].

Considering the gap in the literature, this study focused on the analysis of strength and body composition asymmetry in a sample of long-term active older individuals engaged in Tai Chi Chuan, tennis, or running.

\section{Methods}

The study sample included 97 middle-aged and older individuals (67 men and 30 women; $61.17 \pm 7.56$ years) involved in Tai Chi Chuan (33 individuals; 6 years of practice on average), tennis (29 individuals; 22 years on average), or running (35 individuals 17 years on average). These modalities were selected because of their practicability until old age.

The control group consisted of 59 individuals ( 27 men and 32 women; $61.96 \pm 8.18$ years) living in the same geographical area and not performing regular physical exercise, but doing normal everyday activities (including manual labor).

Exclusion criteria were the presence of physical handicaps, pathologies that might influence the measurements (e.g., significant cardiovascular or pulmonary diseases, endocrine or renal diseases, cancer, or severe inflammatory conditions), metallic prostheses, pacemakers, or limb amputations.

Participant recruitment was performed during the period from January 2018 to April 2019. For each subject, anthropometric and bioimpedance measurements were taken on the same day, beginning with the anthropometric ones.

This study was approved by the Independent Ethical Committee of the A.O.U. of Cagliari (PG/2017/1700). Each participant was informed about the purposes and methods of the study, and signed the informed consent form in order to participate.

\subsection{Anthropometric Measurements and Hand Grip Strength}

Anthropometric measurements were performed by an ISAK-certified anthropometrist, in agreement with international standards [13].

Height $(\mathrm{cm})$ and weight $(\mathrm{kg})$ were taken using a stadiometer (SECA, Hamburg, Germany) and a mechanical scale (SECA, Hamburg, Germany), respectively. Body mass index (BMI) was calculated using the formula weight $/$ height $\mathrm{t}^{2}\left(\mathrm{~kg} / \mathrm{m}^{2}\right)$. The circumferences $(\mathrm{C}, \mathrm{cm})$ of the mid-arm and calf, and lengths $(\mathrm{L}, \mathrm{cm})$ of the arm (distance between the acromion and the stylion) and leg (distance between the great trochanter and the malleolus) were measured on both sides of the body using a body tape (SECA, Hamburg, Germany).

Hand grip strength was measured using a hydraulic dynamometer (Sahean Corporation, MSD, Brussels, Belgium). The participant was asked to stand upright and hold the instrument and squeeze it with the greatest possible force, with his/her elbow flexed at $90^{\circ}[14]$.

The measurement was carried out three times for each side, alternately, in order to guarantee a few seconds of recovery. The maximum value obtained from the three repetitions was used for the analysis.

\subsection{Bioelectrical Measurements}

Bioelectrical impedance measurements were carried out using BIA 101 single-frequency devices (Akern BIA 101 and Akern BIA 101 New Edition, Akern Srl, Firenze, Italy) and Biatrodes electrodes (Akern Srl, Firenze, Italy).

Before each session, the device was checked with a calibrated circuit, whose impedance values are as follows: $R=380 \Omega, X_{c}=47 \Omega( \pm 2 \%$ error). The measurements were taken in the morning and participants were asked not to drink or eat, and to empty their bladders, wear light clothing, and remove metal objects before the examination. 
To assess the body composition of the dominant and non-dominant arms, and the right and left legs, segmental specific bioelectrical impedance vector analysis (BIVA), an accurate procedure recently tested for the evaluation of the segmental body composition, was applied [15]. Resistance $(R)$ and reactance $\left(X_{c}\right)$ values for each body segment were adjusted for a correction factor $(\mathrm{A} / \mathrm{L})$, where $\mathrm{A}\left(\mathrm{cm}^{2}\right)$ is the cross-sectional area $\left(\mathrm{C}^{2} / 4 \pi \mathrm{cm}^{2}\right)$ of the mid-arm and calf, and the $\mathrm{L}(\mathrm{cm})$ is the length of the arm and leg.

Specific impedance $\left(Z_{\mathrm{sp}}\right)$ was calculated as $\left(\mathrm{R}_{\mathrm{sp}}{ }^{2}+\mathrm{X}_{\mathrm{csp}}\right)^{0.5}(\Omega \mathrm{cm})$. The phase angle (PhA) was obtained using the formula $\arctan X_{c} / R 180 / \pi$ (degree).

According to the specific BIVA, the vector length is positively related to variations of FM percentage (\%FM), while PhA is positively related to body cell mass, muscle mass in particular, and to the intracellular/extra cellular water (ICW/ECW) ratio.

\subsection{Statistical Analysis}

The bias between the bioelectrical values obtained with different devices was amended using a correction factor calculated ad hoc [16], and applied to raw data obtained with the Akern BIA 101 New Edition (arm: $R=+0.65, X_{c}=+4.97$; leg: $R=-0.35, X_{c}=+4.48$ ).

Descriptive statistics were calculated for all of the variables and for each sex separately.

Differences in age and anthropometric characters between the active and control groups, considering sex, were analyzed using two-way ANOVA.

Differences between the limbs of the two sides (dominant vs. non-dominant arm, and right vs. left leg) were analyzed using paired Student's t test, considering Cohen's d effect size and Hotelling's $\mathrm{T}^{2}$ test, and were graphically represented in the paired data $\mathrm{RX}_{\mathrm{c}}$ graphs. In these graphs, ellipses overlapping the origin indicated no differences between the bioelectrical values of the two sides. By contrast, non-centered ellipses indicated significant differences between sides, with the effect of $R$ or $X_{c}$ prevailing when the ellipse approached the corresponding axis. The level of asymmetry was compared between limbs, age subgroups ( $<60$ and $\geq 60$ years), and modalities by means of the Hotelling's $\mathrm{T}^{2}$ test.

Statistical analyses were performed using SPSS version 25 (SPSS Inc. Chicago, IL, USA), classic BIVA [17] (and specific BIVA (www.specificbiva.com, accessed on 31 May 2021) software.

\section{Results}

The active participants of both sexes exhibited similar age, higher stature, and lower weight and BMI than the controls (Table 1). Both groups showed a normal pattern of sexual dimorphism, with a higher stature, weight, and BMI among men (Table 1).

Table 1. Descriptive statistics of the control and active individuals and two-way ANOVA for comparisons of the groups.

\begin{tabular}{ccccccccc}
\hline & \multicolumn{2}{c}{ Control } & \multicolumn{2}{c}{ Active } & & \multicolumn{2}{c}{ ANOVA } \\
\cline { 2 - 5 } & Men (27) & Women (32) & Men (67) & Women (30) & & & \\
\cline { 2 - 6 } & Mean SD & Mean SD & Mean SD & Mean SD & & $p_{\text {sex }}$ & $p_{\text {sport }}$ & $p_{\text {sex-sport }}$ \\
\hline Age & $62.13 \pm 8.53$ & $61.66 \pm 7.75$ & $61.24 \pm 7.54$ & $60.84 \pm 7.47$ & & 0.741 & 0.520 & 0.979 \\
Height & $167.92 \pm 6.37$ & $154.28 \pm 7.25$ & $170.56 \pm 6.93$ & $156.70 \pm 6.27$ & 0.000 & 0.032 & 0.925 \\
Weight & $77.61 \pm 10.39$ & $63.56 \pm 9.48$ & $70.92 \pm 9.19$ & $53.39 \pm 7.21$ & & 0.000 & 0.000 & 0.270 \\
BMI & $27.44 \pm 2.60$ & $26.77 \pm 4.01$ & $24.37 \pm 2.71$ & $21.75 \pm 2.71$ & 0.002 & 0.000 & 0.061 \\
\hline
\end{tabular}

BMI: body mass index.

Descriptive and comparative statistics of the bioelectrical values in the dominant and non-dominant arms, and the right and left legs, along with the hand grip strength are shown in Table 2. 
Table 2. Descriptive and comparative statistics of the bioelectrical values and hand grip strength.

\begin{tabular}{|c|c|c|c|c|c|c|c|c|c|c|c|c|c|c|}
\hline \multirow[b]{3}{*}{ ARMS } & \multicolumn{4}{|c|}{ Controls } & \multirow{3}{*}{\multicolumn{2}{|c|}{ Paired $t$-Test }} & \multirow{3}{*}{$\begin{array}{l}\text { Effect } \\
\text { Size }\end{array}$} & \multicolumn{4}{|c|}{ Active } & \multirow{2}{*}{\multicolumn{2}{|c|}{ Paired $t$-Test }} & \multirow{3}{*}{$\begin{array}{l}\text { Effect } \\
\text { Size }\end{array}$} \\
\hline & \multicolumn{2}{|c|}{ Men (27) } & \multicolumn{2}{|c|}{ Women (32) } & & & & \multicolumn{2}{|c|}{ Men (67) } & \multicolumn{2}{|c|}{ Women (30) } & & & \\
\hline & D & ND & D & ND & & & & D & ND & D & ND & & & \\
\hline & Mean SD & Mean SD & Mean SD & Mean SD & $t$ & $p$ & $d$ & Mean SD & Mean SD & Mean SD & Mean SD & $t$ & $p$ & $d$ \\
\hline $\mathrm{R}_{\mathrm{sp}}$ & $266.3 \pm 44.5$ & $264.8 \pm 40.78$ & $330.7 \pm 62.84$ & $328.1 \pm 63.30$ & 0.582 & 0.563 & 0.045 & $231.6 \pm 29.28$ & $232.9 \pm 32.249$ & $274.4 \pm 48.29$ & $284.5 \pm 52.32$ & -1.659 & 0.101 & 0.176 \\
\hline$x_{\text {csp }}$ & $31.6 \pm 7.61$ & $30.1 \pm 6.62$ & $31.3 \pm 8.13$ & $30.6 \pm 8.24$ & 2.438 & 0.018 & 0.303 & $25.8 \pm 4.81$ & $25.3 \pm 5.317$ & $25.3 \pm 5.82$ & $25.5 \pm 5.20$ & 0.826 & 0.411 & 0.082 \\
\hline$Z_{\mathrm{sp}}$ & $268.3 \pm 44.90$ & $266.6 \pm 40.96$ & $332.2 \pm 63.05$ & $329.6 \pm 63.59$ & 0.609 & 0.545 & 0.049 & $233.1 \pm 29.43$ & $234.3 \pm 32.43$ & $275.6 \pm 48.42$ & $285.7 \pm 52.43$ & -1.631 & 0.106 & 0.174 \\
\hline PhA & $6.7 \pm 1.12$ & $6.5 \pm 1.16$ & $5.4 \pm 1.05$ & $5.3 \pm 1.0$ & 1.969 & 0.054 & 0.267 & $6.4 \pm 0.92$ & $6.2 \pm 0.97$ & $5.3 \pm 0.97$ & $5.1 \pm 0.79$ & 1.737 & 0.086 & 0.185 \\
\hline H.G. & $38.1 \pm 9.36$ & $36.9 \pm 8.49$ & $23.5 \pm 5.45$ & $22.6 \pm 5.45$ & 2.885 & 0.005 & 0.337 & $40.6 \pm 7.67$ & $38.0 \pm 7.29$ & $25.3 \pm 5.09$ & $22.3 \pm 5.72$ & 7.080 & 0.000 & 0.697 \\
\hline LEGS & $\mathrm{R}$ & L & $\mathbf{R}$ & L & & & & $\mathbf{R}$ & L & $\mathbf{R}$ & L & & & \\
\hline & Mean SD & Mean SD & Mean SD & Mean SD & $t$ & $p$ & $d$ & Mean SD & Mean SD & Mean SD & Mean SD & $t$ & $p$ & $d$ \\
\hline$R_{\mathrm{sp}}$ & $255.2 \pm 44.42$ & $261.2 \pm 52.30$ & $297.9 \pm 58.52$ & $303.4 \pm 53.67$ & -2.983 & 0.004 & 0.265 & $250.3 \pm 23.49$ & $244.9 \pm 23.53$ & $280.1 \pm 31.12$ & $279.3 \pm 35.04$ & 2.243 & 0.027 & 0.266 \\
\hline$x_{\text {csp }}$ & $31.3 \pm 9.63$ & $30.62 \pm 9.11$ & $31.7 \pm 9.92$ & $33.4 \pm 9.71$ & -1.582 & 0.119 & 0.178 & $29.5 \pm 5.86$ & $29.1 \pm 6.06$ & $30.9 \pm 7.55$ & $31.1 \pm 7.09$ & 0.922 & 0.359 & 0.163 \\
\hline$Z_{\mathrm{sp}}$ & $257.1 \pm 45.00$ & $263.0 \pm 52.82$ & $299.7 \pm 58.94$ & $305.2 \pm 54.18$ & -2.979 & 0.004 & 0.263 & $252.1 \pm 23.80$ & $246.7 \pm 23.86$ & $282.0 \pm 30.70$ & $281.2 \pm 34.88$ & 2.240 & 0.027 & 0.265 \\
\hline PhA & $6.9 \pm 1.40$ & $6.6 \pm 1.20$ & $6.0 \pm 1.33$ & $6.2 \pm 1.16$ & 0.562 & 0.577 & 0.044 & $6.7 \pm 1.01$ & $6.7 \pm 1.07$ & $6.4 \pm 1.99$ & $6.4 \pm 1.70$ & -0.541 & 0.590 & 0.066 \\
\hline
\end{tabular}

$\mathrm{R}_{\mathrm{sp}}$ : specific resistance; $\mathrm{X}_{\mathrm{csp}}$ : specific reactance; $\mathrm{Z}_{\mathrm{sp}}$ : specific vector length; PhA: phase angle; $\mathrm{D}$ : dominant; ND: non-dominant; $\mathrm{R}$ : right; L: left; H.G.: hand grip strength; $t$ : paired Student's t test; $p$ : significance; $d$ : Cohen's d for paired samples.

Active participants showed limb symmetry, as indicated by the paired Hotelling's $\mathrm{T}^{2}$ test and the overlap of the ellipses with the origin of the graph (Figure 1), and as confirmed by the paired Student's $t$ test, which showed no differences between the bioelectrical values of the two sides (Table 2). The only exceptions were the univariate comparisons of Rsp and Zsp (Table 2), which indicated a slightly higher \%FM in the right leg. The symmetrical pattern was similar between the limbs and between age subgroups $(<60$ and $\geq 60$ years). The symmetrical body composition among athletes was also observed considering the different disciplines separately. The paired confidence ellipses of the Tai Chi Chuan, tennis, and running groups were all centered on the origin of the graph, and the bivariate comparison between sides was always not significant (Figure 2), as well as the comparison of asymmetry levels among disciplines. The univariate comparisons also indicated the lack of significant differences between sides for the arms in all of the groups, with the exception of a tendency to higher Rsp values (higher \%FM) in the right legs of runners $(p=0.034)$.
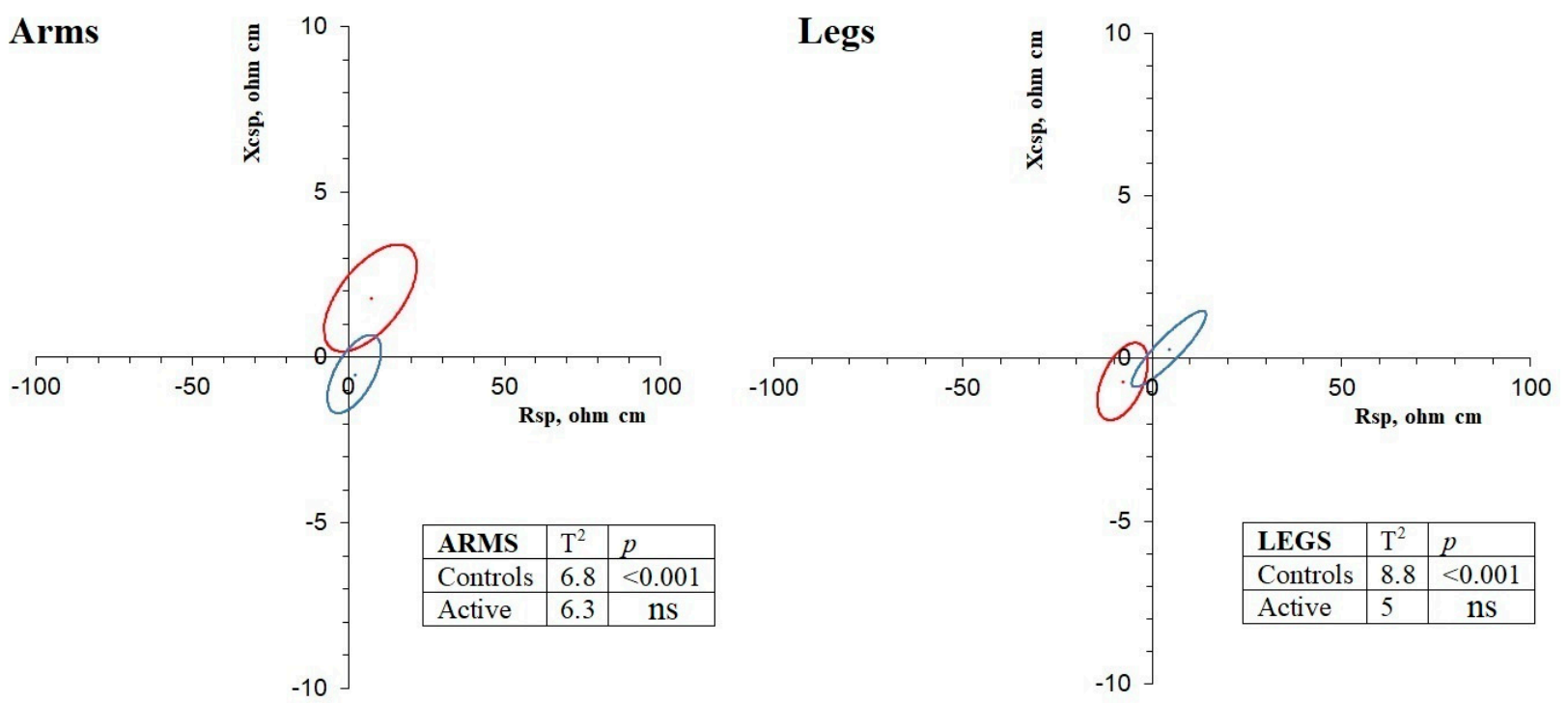

Figure 1. Paired data $\mathrm{RX}_{\mathrm{c}}$ graphs and results of the Hotelling's $\mathrm{T}^{2}$ test for differences between contralateral limbs. Blue: active subjects; Bordeaux: controls. 


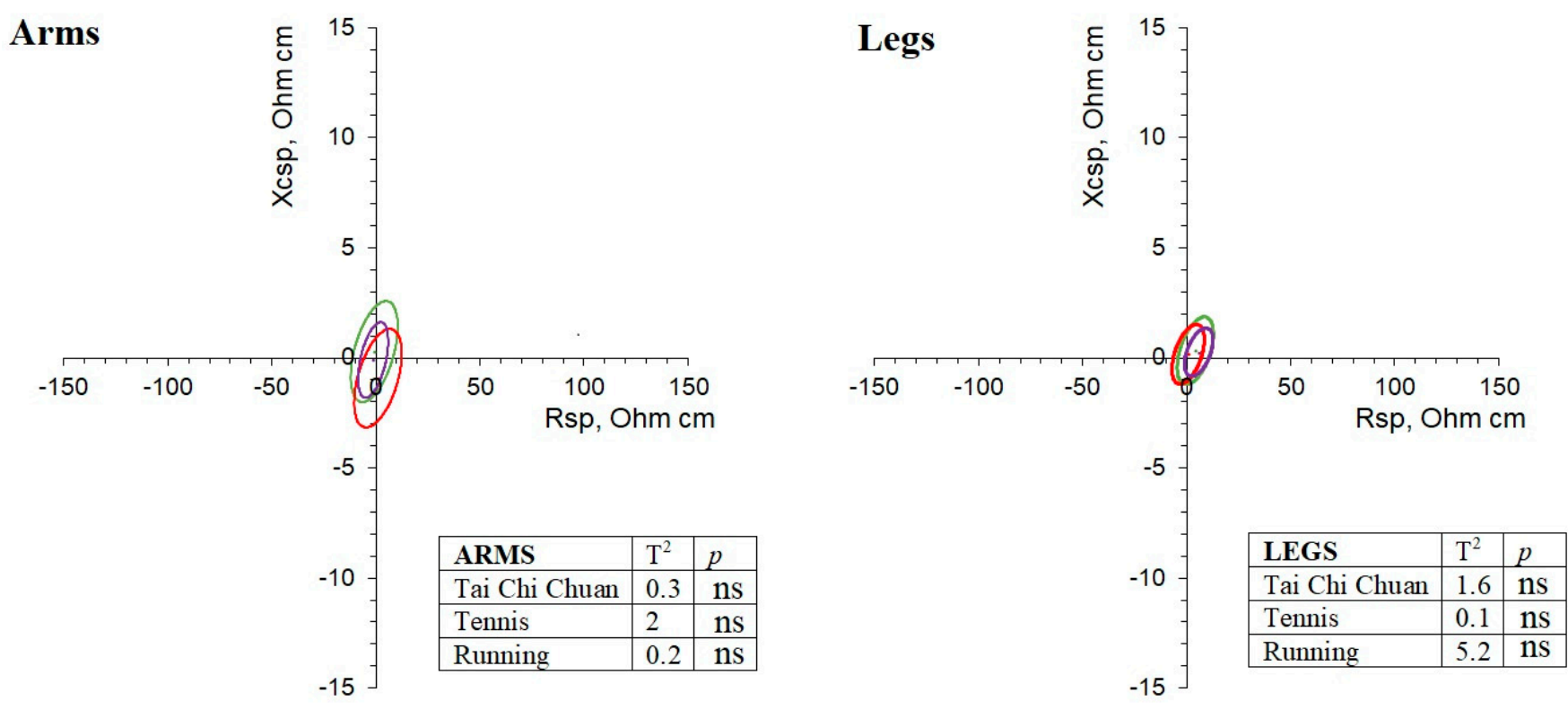

Figure 2. Paired data $\mathrm{RX}_{\mathrm{c}}$ graphs and results of the Hotelling's $\mathrm{T}^{2}$ test for differences between the contralateral limbs. Green: Tai Chi Chuan; red: tennis; purple: running.

By contrast, the control group showed body composition asymmetry, as indicated by the significant paired Hotelling's $\mathrm{T}^{2}$ test results and the position of the ellipses in the graph that at no point overlapped the center (Figure 1). Asymmetry was due to the higher values of $X_{\mathrm{csp}}$ and PhA in the dominant arm and to the higher values of $R_{\mathrm{sp}}$ and $Z_{\mathrm{sp}}$ in the left leg, as indicated by the position of the ellipses and univariate comparisons (Table 2). The legs were significantly more asymmetrical than the arms $\left(T^{2}=9.6, p=0.010\right)$. Age subgroups showed similar levels of asymmetry in both the arms and legs.

Among all of the active and sedentary participants, hand grip strength was significantly higher in the dominant hand (Table 2).

\section{Discussion}

The human body exhibits laterality and the differential use of two limbs can determine asymmetry in body composition and strength. Such features can be influenced by PA, can vary in the life course, and have been shown to be related to injuries in athletes [18-20] and to health outcomes in older people [6-10].

In this study, active individuals showed bilateral symmetry in body composition, with a similar pattern in the upper and lower limbs, in the two age subgroups and in the three disciplines, despite their different training modalities and physical effects. By contrast, the control subjects, regardless of their age, were characterized by limb asymmetry, with higher muscle mass (as indicated by the higher $X_{\text {csp }}$ and $\mathrm{PhA}$ values) in the dominant arm and higher values of $\% F M$ (higher $R_{s p}$ and $Z_{s p}$ ) in the left leg.

In both the control and active groups, the dominant arm showed higher hand grip strength than the opposite one.

Studies on body composition asymmetry in the general population, including older people, show that the dominant leg and arm are characterized by higher values of lean mass [5,21] and less accentuated differences in the FM [5].

The effect of sports on body asymmetry in middle-aged and older adults has mostly been investigated in tennis players, and the results of previous studies are inconsistent. In line with the present study, Piasecki et al. [12] detected symmetrical muscle size in the arms of men. By contrast, Ireland et al. [11] observed greater muscle and bone size in the racquet arm. 
Differences in strength between dominant and non-dominant sides have been frequently observed in healthy adults [22-24]. The asymmetry of hand grip strength in healthy older subjects shows a less homogeneous pattern than that in the general population, and in some studies, a symmetrical strength was observed $[6,8,25]$. Studies on active older participants focused on tennis players consistently detected a greater strength in the dominant arm [11,12,26,27], as in this study.

Strength asymmetry has been related to health outcomes in older people, particularly to functional disabilities, body balance, and falls [7-10], especially among pre sarcopenic and sarcopenic individuals [10].

The role of body composition asymmetry on health is less defined. According to recent studies, body composition symmetry of the lower limbs has a lesser effect on health [21] than strength symmetry $[10,21]$ or good levels of muscle mass in both limbs [28], which could be related to postural control [29].

The results of this study suggest that PA can induce body composition symmetry, likely due to exercise that involves, in some degree, all limbs. By contrast, the age-related reduction of PA characterizing the general population could favor differential use of the contralateral limbs in daily and work-related activities in favor of the dominant side.

The effect of PA on hand-grip strength asymmetry appears to be less pronounced.

More studies are needed to better define the variability of the age-related trend of body symmetry among older individuals, when the physiological trend of reducing muscle mass and strength becomes predominant.

This study has some limitations that should be listed. First, the results are not generalizable to other populations or individuals with clinical conditions and are not directly comparable with studies realized using other bioimpedance devices. Second, the influence of socio-cultural factors, diet, lifestyle, and physical fitness components has not been analyzed. However, to the best of our knowledge, this study is one of the very few studies on body composition asymmetry in aged long-term active individuals of both sexes.

\section{Conclusions}

The results of this study showed that, along with the general positive effect on nutritional status, PA appears to play a role in maintaining the symmetry of body composition, thus indicating a possible positive effect of sport that was not previously detected.

Author Contributions: Conceptualization, S.S. and E.M.; data collection, S.S. and A.M.; formal analysis, S.S.; investigation, S.S., A.M., M.M.C. and E.M.; visualization, S.S.; writing—original draft, S.S. and E.M.; writing-review and editing, S.S., A.M., M.M.C. and E.M. All authors have read and agreed to the published version of the manuscript.

Funding: This research received no external funding.

Institutional Review Board Statement: The study was conducted according to the guidelines of the Declaration of Helsinki, and approved by the Ethics Committee of University of Cagliari (protocol code PG/2017/1700, 25 January 2017).

Informed Consent Statement: Informed consent was obtained from all subjects involved in the study.

Data Availability Statement: The data that support the findings of this study are available from the corresponding author, upon request.

Acknowledgments: We are most grateful to all of the volunteers. Silvia Stagi gratefully acknowledges the Sardinia Regional Government for the financial support of her Ph.D. scholarship (P.O.R. Sardegna F.S.E. Operational Programme of the Autonomous Region of Sardinia, European Social Fund 2014-2020-Axis III Education and training, Thematic goal 10, Priority of investment 10ii), Specific goal 10.5, Action partnership agreement 10.5.12.

Conflicts of Interest: The authors declare no conflict of interest. 


\section{References}

1. McGrath, R.; Tomkinson, G.R.; LaRoche, D.P.; Vincent, B.M.; Bond, C.W.; Hackney, K.J. Handgrip Strength Asymmetry and Weakness May Accelerate Time to Mortality in Aging Americans. J. Am. Med. Dir. Assoc. 2020, 21, 2003-2007.e1. [CrossRef]

2. Liberman, K.; Forti, L.N.; Beyer, I.; Bautmans, I. The effects of exercise on muscle strength, body composition, physical functioning and the inflammatory profile of older adults: A systematic review. Curr. Opin. Clin. Nutr. Metab. Care 2017, 20, 30-53. [CrossRef]

3. Stagi, S.; Doneddu, A.; Mulliri, G.; Ghiani, G.; Succa, V.; Crisafulli, A.; Marini, E. Lower percentage of fat mass among tai chi chuan prac-titioners. Int. J. Environ. Res. Public Health 2020, 17, 1232. [CrossRef] [PubMed]

4. WHO Guidelines on Physical Activity and Sedentary Behaviour; World Health Organization: Geneva, Switzerland, 2020.

5. Hinton, B.J.; Fan, B.; Ng, B.; Shepherd, J.A. Dual energy X-ray absorptiometry body composition reference values of limbs and trunk from NHANES 1999-2004 with additional visualization methods. PLoS ONE 2017, 12, e0174180. [CrossRef] [PubMed]

6. Skelton, D.A.; Kennedy, J.; Rutherford, O.M. Explosive power and asymmetry in leg muscle function in frequent fallers and non-fallers aged over 65. Age Ageing 2002, 31, 119-125. [CrossRef] [PubMed]

7. Portegijs, E.; Sipilä, S.; Alen, M.; Kaprio, J.; Koskenvuo, M.; Tiainen, K.; Rantanen, T. Leg Extension Power Asymmetry and Mobility Limitation in Healthy Older Women. Arch. Phys. Med. Rehabil. 2005, 86, 1838-1842. [CrossRef] [PubMed]

8. Laroche, D.P.; Cook, S.B.; Mackala, K. Strength Asymmetry Increases Gait Asymmetry and Variability in Older Women. Med. Sci. Sports Exerc. 2012, 44, 2172-2181. [CrossRef] [PubMed]

9. Chon, J.; Kim, H.-S.; Lee, J.H.; Yoo, S.D.; Yun, D.H.; Kim, D.H.; Lee, S.A.; Han, Y.J.; Soh, Y.; Kim, Y.; et al. Association Between Asymmetry in Knee Extension Strength and Balance in a Community-Dwelling Elderly Population: A Cross-Sectional Analysis. Ann. Rehabil. Med. 2018, 42, 113-119. [CrossRef] [PubMed]

10. McGrath, R.; Clark, B.C.; Cesari, M.; Johnson, C.; Jurivich, D.A. Handgrip strength asymmetry is associated with future falls in older Americans. Aging Clin. Exp. Res. 2020, 1-9. [CrossRef]

11. Ireland, A.; Maden-Wilkinson, T.; Ganse, B.; Degens, H.; Rittweger, J. Effects of age and starting age upon side asymmetry in the arms of veteran tennis players: A cross-sectional study. Osteoporos. Int. 2014, 25, 1389-1400. [CrossRef]

12. Piasecki, M.; Ireland, A.; Piasecki, J.; Degens, H.; Stashuk, D.W.; Swiecicka, A.; Rutter, M.K.; Jones, D.A.; McPhee, J.S. Long-Term En-durance and Power Training May Facilitate Motor Unit Size Expansion to Compensate for Declining Motor Unit Numbers in Older Age. Front. Physiol. 2019, 10, 449. [CrossRef] [PubMed]

13. Lohman, T.G.; Roche, A.F.; Martorell, R. Anthropometric Standardization Reference Manual; Human Kinetics Books: Champaign, IL, USA, 1998.

14. Hillman, E.T.; Nunes, Q.M.; Hornby, S.T.; Stanga, Z.; Neal, K.R.; Rowlands, B.J.; Allison, S.P.; Lobo, D.N. A practical posture for hand grip dynamometry in the clinical setting. Clin. Nutr. 2005, 24, 224-228. [CrossRef] [PubMed]

15. Stagi, S.; Irurtia, A.; Rosales Rafel, J.; Cabras, S.; Buffa, R.; Carrasco-Marginet, M.; Castizo-Olier, J.; Marini, E. Segmental body compo-sition estimated by specific BIVA and dual-energy X-ray absorptiometry. Clin. Nutr. 2021, 40, 1621-1627. [CrossRef] [PubMed]

16. Stagi, S. Long-Term Effects of Sport on Segmental Body Composition: A Study in Adult and Elderly Subjects. Ph.D. Thesis, University of Cagliari, Cagliari, Italy, 2021.

17. Piccoli, A.; Pastori, G. BIVA Software 2002; Department of Medical and Surgical Sciences, University of Padova: Padova, Italy, 2002.

18. Hart, N.H.; Nimphius, S.; Spiteri, T.; Newton, R.U. Leg strength and lean mass symmetry influences kicking performance in Aus-tralian Football. J. Sports Sci. Med. 2014, 13, 157.

19. Jordan, M.J.; Aagaard, P.; Herzog, W. Lower limb asymmetry in mechanical muscle function: A comparison between ski racers with and without ACL reconstruction: Bilateral asymmetry in ACL-R ski racers. Scand. J. Med. Sci. Sports 2015, 25, e301-e309. [CrossRef]

20. Nescolarde, L.; Yanguas, J.; Medina, D.; Rodas, G.; Rosell-Ferrer, J. Assessment and follow-up of muscle injuries in athletes by bioimpedance: Preliminary results. In Proceedings of the 2011 Annual International Conference of the IEEE Engineering in Medicine and Biology Society, Boston, MA, USA, 30 August-3 September 2011; pp. 1137-1140. [CrossRef]

21. Lee, E.J.; Lee, S.A.; Soh, Y.; Kim, Y.; Won, C.W.; Chon, J. Association between asymmetry in lower extremity lean mass and functional mobility in older adults living in the community: Results from the Korean Frailty and Aging Cohort Study. Medicine 2019, 98, e17882. [CrossRef]

22. Coren, S.; Porac, C.; Duncan, P. A behaviorally validated self-report inventory to assess four types of lateral preference. J. Clin. Neuropsychol. 1979, 1, 55-64. [CrossRef]

23. Petersen, P.; Petrick, M.; Connor, H.; Conklin, D. Grip Strength and Hand Dominance: Challenging the 10\% Rule. Am. J. Occup. Ther. 1989, 43, 444-447. [CrossRef]

24. Incel, N.A.; Ceceli, E.; Durukan, P.B.; Erdem, H.R.; Yorgancioglu, Z.R. Grip strength: Effect of hand dominance. Singap. Med. J. 2002, 43, 234-237.

25. Koda, H.; Kai, Y.; Murata, S.; Osugi, H.; Anami, K.; Fukumoto, T.; Imagita, H. Relationship Between Muscle Strength Asymmetry and Body Sway in Older Adults. J. Aging Phys. Act. 2018, 26, 457-461. [CrossRef]

26. Maughan, R.J.; Abel, R.W.; Watson, J.S.; Weir, J. Forearm composition and muscle function in trained and untrained limbs. Clin. Physiol. 1986, 6, 389-396. [CrossRef] [PubMed] 
27. Vodak, A.P.; Savin, W.M.; Haskell, W.L.; Wood, P.D. Physiological profile of middle-aged male and female tennis players. Med. Sci. Sports Exerc. 1980, 12, 159-163. [CrossRef] [PubMed]

28. Mertz, K.H.; Reitelseder, S.; Jensen, M.; Lindberg, J.; Hjulmand, M.; Schucany, A.; Andersen, S.B.; Bechshoeft, R.L.; Jakobsen, M.D.; Bieler, T.; et al. Influence of between-limb asymmetry in muscle mass, strength, and power on functional capacity in healthy older adults. Scand. J. Med. Sci. Sports 2019, 29, 1901-1908. [CrossRef] [PubMed]

29. Bertolini, G.N.; de Alencar Silva, B.S.; Dos Santos, V.R.; de Anchieta Messias, I.; Ribeiro, J.P.J.; Marini, E.; Gobbo, L.A. Are bioelectrical parameters and functionality associated with postural control in the elderly? Clin. Biomech. 2021, 82, 105258. [CrossRef] [PubMed] 